DOI: $10.20396 /$ cel.v62i0.8654477

(c) $(1) \Theta$

\title{
UMA ANÁLISE DOS DIZERES SOBRE A VOZ DE SUCESSO MIDIÁTICO
}

\author{
UNE ANALYSE DES DICTONS SUR LA VOIX DU SUCCÈS \\ MÉDIATIQUE
}

\author{
THIAGO BARBOSA SOARES ${ }^{1}$
}

\begin{abstract}
RESUMO: Este artigo tem por objetivo analisar discursos produzidos e veiculados pela mídia brasileira contemporânea sobre o que se poderia chamar de as vozes do sucesso midiático. Mais precisamente, são descritos e interpretados os procedimentos de produção de sentidos em enunciados constituídos e formulados no interior do discurso midiático brasileiro que trata manifestamente da voz de sujeitos cujo sucesso decorre em princípio de seu desempenho vocal. Desse modo, ao ser considerado o postulado da Análise do Discurso, formulado por Pêcheux, de que sujeito e sentido se constituem ao mesmo tempo no movimento histórico, entende-se que os dizeres acerca da voz de sucesso produzem, concomitantemente, os sentidos e os sujeitos que circulam socialmente. Ante esse quadro estruturante, foi investigado o que se diz e como é enunciada a voz no discurso do sucesso, na atual sociedade brasileira e as diferenças no tratamento dispensado à voz daqueles que figuram no mundo midiático, em específico, quais distinções podem existir no tocante à produção de sentidos das vozes de sucesso midiático quando disseminadas pelo mesmo veículo de difusão. Para tanto, contamos com dois textos da revista Carta Capital, publicados respectivamente em 2013 e em 2015.
\end{abstract}

Palavras-chave: Análise do Discurso; Mídia; Voz; Sucesso.

RÉSUMÉ: Cet article a pour objectif d'analyser les discours produits et véhiculés par les médias brésiliens contemporains sur ce que l'on pourrait appeler le succès des médias. Plus précisément, nous décrivons et interprétons les procédures de production de significations dans des déclarations faites et formulées dans le discours médiatique brésilien, qui traite évidemment de la voix des sujets dont le succès provient de leur performance vocale. Ainsi, lorsque nous considérons le postulat de l'analyse du discours formulé par Pêcheux selon lequel sujet et sens sont à la fois constitués dans le mouvement historique, nous comprenons que les mots sur la voix du succès produisent à la fois les sens et les sujets qui mouvement social. Dans ce cadre, nous examinons ce qui est dit et comment est exprimé le discours sur le succès dans la société brésilienne actuelle et les différences de traitement de la voix de ceux qui figurent dans le monde des médias, en particulier, des distinctions qui peuvent exister en matière de production. des voix des médias performants lorsqu'elles sont diffusées par le même véhicule de diffusion. Pour ce faire, nous avons deux textes du magazine Carta Capital, l'un publié en 2013 et l'autre en 2015.

Mots-clés: Analyse du Discours; médias; voix; succès.

${ }^{1}$ Universidade Federal do Tocantins (UFT), Porto Nacional, TO, Brasil. thiagobsoares@bol. com.br

Orcid: https://orcid.org/0000-0003-2887-1302 


\section{INTRODUÇÃO}

A voz e o mercado foram intrinsecamente ligados quando entraram em contato com a necessidade humana em difundir, de maneira eficiente, a ideologia consumista. A partir dessa carência, surgem diversos efeitos midiáticos dentre eles o da voz de sucesso o qual impacta consideravelmente na fabricação de sujeitos e de sentidos (SOARES, 2020b, p. 23-24). Neste texto, empreende-se uma análise cujo objetivo é descrever e interpretar o funcionamento dos dizeres acerca das vozes do sucesso midiático. Para tanto, será feito o emprego do referencial teórico e metodológico da Análise do Discurso, derivada dos trabalhos e pressupostos de Michel Pêcheux e de seu grupo. Entretanto, será mobilizado, assim que se fizer necessário, outros textos e autores que possam iluminar o objeto de investigação proposto. Serão observados, portanto, as regularidades e as diferenças marcadas no tecido discursivo que frequenta dois textos, Para ler Michael Jackson (2013) e Billie Holiday (2015), inseridos no universo de circulação virtual da revista Carta Capital.

Para tanto, também se faz necessário esclarecer a relação intrínseca existente entre a fala como efeito de verdade, a voz, a mídia e o mercado. Estes, nos primórdios da difusão radiofónica, forjam os instrumentos ideais para a inoculação ${ }^{2}$ do sucesso em sujeitos e sentidos. Sentidos estes que, atrelado ao poder midiático e sua maquinaria, passam por processos de estabilização e deslizamento. Consequentemente, no cruzamento entre discursos, "que não somente ao do sucesso, como também ao de um certo tipo de beleza, ao da riqueza, entre outros" (SOARES; PIOVEZANI, 2018, p. 135), esses efeitos de sentido espelham modelos a serem seguidos. Modelos que relativamente condicionam os sujeitos através de determinados efeitos de verdade.

Nessa perspectiva, o mercado, sustentado por meio da mídia que se vale do entrecruzamento de discursos, especialmente do discurso do sucesso, é constituído por vários difusores, dentre eles a voz, não confundida, nessas considerações, com a voz de sucesso, um artefato cultural comercializável. Essas vozes, por sua vez, são classificadas por diversas interpelações (a voz do radialista, do apresentador, do cantor, do comediante, etc.) e se encontram carregadas de sentidos nos quais o efeito de verdade tende a manifestar-se.

Dito isso, é preciso esclarecer que esse efeito de verdade, produzido pela voz, "surge da subjetividade do indivíduo em sua relação com o mundo, criando uma adesão ao que pode ser julgado verdadeiro" (CHARAUDEAU, 2013, p. 49), não somente "pelo fato de que é compartilhável com outras pessoas e se inscreve nas normas de reconhecimento do mundo", como quer Charaudeau (2013, p. 49), pois aceitar somente esse fato seria desconsiderar o que Pêcheux postulou no esclarecimento sobre a teoria das ideologias:

${ }^{2} \mathrm{O}$ termo "inoculação" é utilizado para enfatizar a introdução, por parte do marketing, do ideal consumista de forma intencional e paulatina, através dos efeitos de sucesso em léxicos tipicamente comuns. 
A área da ideologia não é de modo algum o único elemento, dentro do qual se efetuaria a reprodução/transformação das relações de produção e uma formação social; isso seria ignorar as determinações econômicas que condicionam 'em última instância' essa produção/transformação, no próprio interior da produção econômica (2014, p. 129).

Dessas colocações, se compreende que tal efeito de verdade compartilhável através da voz surge também por condicionamentos impostos pelas determinações econômicas as quais, por sua vez, são determinadas primeiramente por necessidades humanas e depois pelo comportamento exacerbado de aquisição de bens e serviços não essenciais. Isto é, a voz da verdade midiática funde consumo à satisfação interpessoal e intrapessoal (prazer, sucesso, felicidade, etc.) de maneira a transformar o ato consumista em ato de consumo. Em outras palavras, transformar ilusões mercadológicas em necessidades básicas. Esse discurso se adensa mais ainda quando a mídia se vale dos sujeitos de sucesso, "sendo, então, atores, apresentadores, cantores, modelos etc." (SOARES; PIOVEZANI, 2018, p. 135).

Nessa perspectiva, observa-se que "efeito de verdade" não significa "valor de verdade", pois "fazer parecer é um dos mais essenciais usos da mídia. Por sempre usurpar a realidade do seu papel no seio social acaba por outra criar" (SOARES, 2018b, p. 180). De outro modo, a realidade mencionada é substituída por representações, símbolos dos quais a voz atua não só como difusor, mas também como artefato. Isto é, os dizeres sobre as vozes no espaço midiático funcionam como um mecanismo altamente denso na reprodução dos discursos sociais (ANGENOT, 2015), por se valerem de artefatos culturais (os livros, as músicas, os espaços urbanos, etc.) carregados de simbologia que evocam e estimulam os desejos humanos em suas diversas atividades sensoriais: como ler e escutar, por exemplo.

Nessas considerações, não existindo literalidade para a Análise do Discurso e, sobretudo, sopesando os efeitos de sentido como uma variação da materialidade ideológica, a qual interpela os indivíduos em sujeito (ALTHUSSER, 1992), torna-se, portanto, necessário rastrear quais efeitos são fabricados e como são veiculados nas formulações cuja voz é constada como um núcleo associativo, arregimentador do sucesso de certas personalidades midiáticas em diversos campos, especialmente, no musical. Em vista dessa proposta, as próprias análises trarão à luz os dispositivos de construção textual e de mobilização dos discursos integrantes da constituição dos dizeres sobre as vozes do sucesso midiático e de seus efeitos.

\section{A VOZ DE SUCESSO MIDIÁTICO}

\subsection{Para ler Michael Jackson}

(Publicado em 07/03/2013)

Biografia contestada do astro pop analisa a origem aberrante da indústria de entretenimento dos Estados Unidos 
Segundo o jornalista Bill Wyman, na revista The New Yorker, Jackson realizou a aspiração de muitos artistas ao cruzar fronteiras de mercado. "Ele conquistou uma popularidade e uma autonomia econômica nunca antes sonhadas por um artista negro", escreveu. "Em meados dos anos 1980 era o maior astro negro da história ao evitar percepções convencionais de negritude." Wyman afirma que o cantor, com sua voz infantil, aparência andrógina e pele cada vez mais branca, tornou literal o desejo de uma estética universal.

O recorte da matéria acima é oriundo do segmento Cultura da revista Carta Capital. Noticiar uma biografia parece estar mais bem alinhado com uma concepção de cultura mais elitista, na qual o livro é o artefato cultural de maior valor simbólico na estruturação da cultura. Se, por um lado, é, em princípio, de leitura que se trata a reportagem acima, por outro, é de uma personalidade de sucesso, o que denuncia, ou pelo menos elucida, o fato de o sucesso atualmente ser considerado integrante da cultura. Por isso, o incentivo dado pelo título da notícia de se ler Michael Jackson ${ }^{3}$, porquanto a literatura, que nunca saiu ilesa das tendências da época, é um dos redutos do sucesso produzido pela mídia. Michael Jackson é tanto para ser ouvido, quanto para ser lido.

Para ler Michael Jackson se inscreve no interdiscurso da recomendação de leitura por fazer uso da fórmula, em sentido amplo, para ler... Michael Jackson não era um escritor para ser lido metonimicamente por meio de sua obra, mas, sim, um cantor. Ler e ouvir são práticas distintas, do ponto de vista semântico, de tal modo que, ao se figurarem como recomendação, em uma manchete, selecionam o público leitor. Para ouvir Michael Jackson remeteria a uma coletânea de músicas. No entanto, a formulação Para ler Michael Jackson não exclui aqueles que ouviam e ouvem suas canções para se centrar em quem lê, ao contrário, chama ouvintes a se tornarem leitores, e, no limite, leitores a se tornarem ouvintes.

Dito isso, percebe-se que o enunciado para ler Michael Jackson joga com o equívoco e por isso permite a adesão a outros sentidos. Lacan (1975, p. 302) ressalta que "nossas palavras que tropeçam são palavras que confessam. Elas revelam uma verdade de detrás". Esse "tropeçar", intencionalmente produzido pela mídia é justamente o que torna possível a revelação da dupla escolha ao sujeito: o ler marcado lexicalmente e o ouvir, afetando sujeitos também pelo não-dito.

Para o discurso midiático, por intermédio do discurso do sucesso, transformar fãs de um vulto do setor musical em consumidores de outro artefato de venda, livros dessa personagem, é excelente negócio, pois há a movimentação de mais um nicho de lucros que, por sua vez, aquece outros tantos. Para ler Michael Jackson é sintoma materializado linguisticamente do que afirmou Althusser (1992, p. 94): "A ideologia interpela os indivíduos enquanto sujeitos". A ideologia do sucesso visa interpelar (o já interpelado) o ouvinte de Michael Jackson em um leitor e, como ricochete, tornar não ouvintes em leitores, por conseguinte, estes serem interpelados em consumidores das músicas do cantor. Estratégia discursiva

${ }^{3}$ Os itálicos encontrados ao longo desse texto são recursos metodológicos para indicar a retomada do intradiscurso (eixo da formulação), ou seja, de enunciados em processo de análise. 
de reaproveitamento massivo dos existentes recursos comercializados somada à capitação de mais adeptos ao sucesso do astro pop.

A partir de considerações relativamente semelhantes a essas, Adorno e Horkheimer (1985, p. 194), ao discutirem a sociedade de massa e o papel dessas celebridades para os conglomerados industriais, atestam o que foi dito acima ao afirmar que "os astros são apenas os moldes para uma indústria de confecção de dimensões mundiais e para a tesoura da justiça legal e económica, com a qual se eliminam as últimas pontas dos fios de linha". Por ter dimensões mundiais, a indústria precisa se valer desse jogo de equívoco ler/escrever para continuar se retroalimentando em um fluxo autossustentável.

Para ler Michael Jackson ganha seus contornos de justificativa (do porquê ler Michael Jackson) no interior da matéria. O subtítulo Biografia contestada do astro pop analisa a origem aberrante da indústria de entretenimento dos Estados Unidos auxilia no rastreio das condições de produção e emergência da própria notícia, pois "é impossível analisar um discurso como um texto, isto é, como uma sequência linguística fechada sobre si mesma, mas que é necessário referi-lo ao conjunto de discursos possíveis" (PÊCHEUX, 2010, p. 78, itálicos do autor). Em vista disso, o sintagma Biografia contestada do astro pop remonta não só a para ler Michael Jackson como também ao sucesso das celebridades midiáticas, ou seja, ao discurso do sucesso que as encarna. Quem tem uma biografia contestada que analisa a origem aberrante da indústria de entretenimento dos Estados Unidos sendo recomendada em título de uma revista estrangeira? A resposta é o já-dito que recupera o sujeito do discurso do sucesso, o astro pop, Michael Jackson.

Ao seguir o fio do discurso tecido no texto, encontra-se a caracterização de biografia pela unidade lexical contestada, denotando um possível avesso do que se veicula comumente por apenas biografia. Noutras palavras, a biografia em questão não só trará apenas os fatos, mas também os contestará com o argumento dos mesmos terem sido edificados pela indústria de entretenimento dos Estados Unidos. Esse é, então, mais um mecanismo textual de (re)construção discursiva do sucesso de Michael Jackson, porquanto dirá a "verdade" por contestação, que não deve ser outra coisa senão a heroicização do cantor. Além de ser uma biografia contestada, a obra analisa a origem aberrante da indústria de entretenimento dos Estados Unidos. O modificador aberrante traz ao trecho um traço da formação discursiva que critica a indústria de entretenimento dos Estados Unidos.

Ora, a face perversa da indústria cultural de entretenimento norte-americana já fora escrutinada a fundo por muitos outros, sobretudo pelos membros da Escola de Frankfurt. Não sem razão que Adorno e Horkheimer (1985, p. 118-119) afirmam que "a fusão atual da cultura e do entretenimento não se realiza apenas como depravação da cultura, mas igualmente como espiritualização forçada da diversão". Eles ainda acrescentam que "quanto mais firmes se tornam as posições da indústria cultural, mais sumariamente ela pode proceder com as necessidades dos consumidores, produzindo-as, dirigindo-as, disciplinando-as e, inclusive suspendendo a diversão" (ibid.).

Adorno e Horkheimer (1985) demonstram, em seu tempo, o poder da indústria cultural de entretenimento de coisificar a vida. Uma biografia de Michael 
Jackson é integrante inevitável do processo de glorificação de uma celebridade pelo aparato dessa indústria aberrante. "Criticar para conquistar" serviria como um rótulo para muitos dos que representam o sucesso e pretendem angariar mais fãs asseverando a desaprovação à mídia ou à indústria de entretenimentos.

Como outro recurso de discursivização do sucesso de Michael Jackson, a notícia tem estruturas sintáticas cujos modelos são as formas de discurso indireto e direto, cada qual gerando efeitos de sentidos complementares na retomada e constituição do interdiscurso do qual o intradiscurso extrai sua significação. Então, para se dizer que Jackson realizou a aspiração de muitos artistas ao cruzar fronteiras de mercado, evoca-se a figura de um jornalista norte-americano, Bill Wyman, da revista de mesma nacionalidade, empregando aí a forma de discurso indireto. Sobre esse tipo de expressão, Platão e Fiorin explanam:

O discurso indireto não se interessa pela individualidade do falante revelada no modo como ele diz as coisas. Por isso é a forma preferida nos textos de natureza filosófica, científica, política, etc., quando se expõem as opiniões dos outros com a finalidade de criticá-las, rejeitá-las ou incorporá-las (p. 185; grifo nosso).

Diante das demais partes desta reportagem, pode-se afirmar que a opinião do jornalista Bill Wyman foi incorporada ao conjunto de ideais exteriorizadas. Todavia, o desempenho do sujeito responsável pelo dito não deixa de ser levado em consideração, pois ele não é qualquer pessoa, é jornalista na revista The New Yorker. Portanto, o efeito de "objetividade analítica", tal como entendido por Platão e Fiorin (1993, p. 184), fica comprometido pela parcialidade impressa no texto. E na busca de criar o efeito de verdade, o discurso direto é mobilizado em: "Ele conquistou uma popularidade e uma autonomia econômica nunca antes sonhadas por um artista negro" e "Em meados dos anos 1980 era o maior astro negro da história ao evitar percepções convencionais de negritude." "Ao optar pelo discurso direto, o narrador cria um efeito de verdade, dando a impressão de que preservou a integridade do discurso citado e a autenticidade do que reproduziu" (PLATÃO; FIORIN, 1993, p. 184).

A reportagem serve-se de tantos mecanismos, ao (re)construir o sucesso do cantor, que não é preciso ler a biografia para se saber que ela o enaltece ainda mais. Nesse aspecto, o discurso indireto é repetido no seguinte fragmento: Wyman afirma que o cantor, com sua voz infantil, aparência andrógina e pele cada vez mais branca, tornou literal o desejo de uma estética universal. Aqui múltiplos elementos carecem de exame, como a negritude do cantor, sua voz e o desejo de uma estética universal. A começar pela negritude, progressivamente rechaçada por Michael Jackson em sua própria pele, cujo principal sinal é o de materialização do discurso racista de discriminação.

$O$ astro pop desempenhou vivamente o papel de agente do sucesso como uma celebridade com enorme visibilidade, no entanto foi impelido pelo discurso da discriminação a marcar a ideologia dominante na pele, que de negra passou a praticamente branca. Ora, o discurso do sucesso é o discurso das classes detentoras dos meios de produção da vida social - geradoras fundamentais das desigualdades e discriminações - discurso esse que é travestido das significações de glória 
midiática, de autonomia financeira, de realização pessoal e profissional, tão potente que algemou boa parte do potencial combativo do cantor na luta contra o racismo. Quem poderia ter maior aderência do grande público, de seus fãs e demais setores da sociedade para se opor às práticas de racismo foi justamente quem comprovou que "Toda ideologia interpela os indivíduos concretos enquanto sujeitos concretos, através do funcionamento da categoria de sujeito" (ALTHUSSER, 1992, p. 96).

A ideologia tem suas raízes profundas no inconsciente, agindo, muitas vezes, sorrateiramente na elaboração dos sujeitos "bons" (ibid.), por isso quem não the reconhece e the é contrário chama-se sujeito "mau" ou subversivo. O sujeito do sucesso não pode ser mau, ao contrário, precisa ser um sujeito bom para ter seus atributos inflamados pela mídia. "A mídia nesse sentido, não é apenas o instrumento de imposição legitimada de um padrão, mas também a arena das disputas de espaço pela construção de práticas significativas dentro de uma cultura em luta" (MARTINO, 2010, p. 147, grifos do autor). A pele cada vez mais branca gesta no interdiscurso os sentidos aos quais todos que não são brancos estão submetidos, 0 clareamento da pele de um astro pop são alguns de seus efeitos.

A mídia conserva a hegemonia ideológica em suas práticas discursivas, de modo a perpetuar o edifício do sucesso e seus atributos, num apelo sutil a um item da sentença do imperador Vespasiano: "pão e circo para o povo". Eis, assim, que a voz do cantor surge no tecido textual unida à aparência andrógina como marca do sucesso de Michael Jackson. A voz do astro pop é caracterizada como infantil, nos remetendo ao início da ópera na Itália em que os cantores eram castrados em tenra idade para manterem um timbre infantil ou feminino. A esse respeito, o filme Farinelli, Il Castrato (direção de Gérard Corbiau, 1994) demonstra em seu enredo como a fama de um jovem castrado foi se estabelecendo como uma espécie de padrão.

Wajcman (2012), acerca do cantor de ópera castrado, diz: «Le castrat tient en quelque sorte la position de la voix off, disant la raison du désir qui lie l'homme à la femme. Voix ailleurs, il est la voix du désir, son Autre à la fois présent et

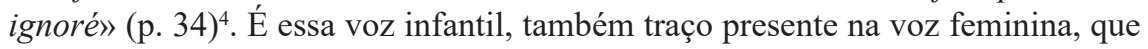
trouxe a muitos cantores de ópera de séculos passados e a Michael Jackson o reconhecimento e a fama. A voz infantil como um desejo do outro, desejo no qual é arrolado homem e mulher, tal como alude Wajcman; por ser a voz de fora, isto é, nem a voz do homem, nem a voz da mulher, mas lhes constituindo na origem, é a voz do desejo reprimido. A voz dita infantil realiza o retorno do que já não é mais, o encontro com a falta insistentemente presente no Outro e o encadeamento do retorno à falta.

Portanto, os sintagmas voz infantil e astro pop sustentam e dão vazão a discursos sobre a voz e lhes imprimem as peculiaridades do discurso do sucesso assentadas no acabamento mercadológico da voz. Esse efeito de sucesso que a estética da voz produz é reforçado também por uma longa cultura midiática

${ }^{4}$ Em tradução livre: "O castrado mantém de algum modo a posição da voz de fora, dizendo que é razão para o desejo de que liga o homem a mulher. Voz é, além disso, a voz do desejo, seu Outro presente e ignorado." 
amparada pela já mencionada era radiofônica. Charaudeau (2013, p. 106) comenta: "diz-se que a voz, com suas características de timbre, de entonação, de fluência e de acentuação, é reveladora do que comumente é chamado de 'estado de espírito' de quem fala, isto é, dos movimentos que perpassam sua afetividade". Tal estado de espírito faz parte da completude do desejo de uma estética universal, assim como a voz infantil, aparência andrógina e a pele branca como a literalidade desse desejo. Desse modo, com esses sintagmas, não só é criado o efeito de exaltação da figura do cantor como também são estabelecidos componentes hegemônicos da estética do sucesso.

A criação de um padrão estético e sua propagação pela mídia é um elemento na construção de hegemonias, identidades e práticas entre os receptores, mais ou menos dispostos a pensar nesses elementos quando de sua apropriação da mensagem dos meios (MARTINO, 2010, p. 147).

O desejo de uma estética universal é, no fio do discurso, uma préconstrução do próprio sucesso. A capitalização da estética do sucesso dura o tempo da representatividade midiática de seu sujeito. Quando essa cessa, outra personalidade assume o lugar ou o mercado em conjunto com a mídia lança produtos que difundam e vendam a celebridade - isso ocorrerá invariavelmente, dadas as crescentes demandas preparadas para o consumo - aproveitando, assim, do alastramento do seu sucesso, como uma biografia Para ler Michael Jackson.

Portanto, a pré-construção do próprio sucesso aponta também para dois elementos lexicais que remetem às características angelicais, a saber, a pureza (infantil) e a não definição do sexo dos anjos (aparência andrógina). Há em marcha um jogo de equívoco, permitindo a ampliação do campo mercadológico através da interpelação de sujeitos e sentidos, tendo o efeito de sucesso como construção de uma interseção sacro-pop. É nesse rastreio do sagrado e do popular, nessa tensão entre as regularidades e as diferenças que será também analisado o segundo texto proposto.

\subsection{Billie Holiday}

(Publicado em 08/04/2015).

Adjetivos como "ícone" e "autêntica" não bastam para descrever a importância de "Lady Day". Poucos conseguiram dar vida à música como ela: sua influência é sentida cem anos após seu nascimento

"Ela tinha apenas 17 anos, um pouco acima do peso, perfeitamente bela e absolutamente desconhecida. E cantou como se realmente tivesse vivido [o que a canção dizia]." Assim o produtor musical John Hammond descreve seu primeiro encontro com Billie Holiday. Ele foi confrontado com a voz única dela em 1933, numa casa noturna em Nova York.

No recorte acima, a seção de Cultura da revista traz informações sobre uma cantora estadunidense, caracterizando, com isso, um enfoque, no quesito cultural, abundantemente estrangeiro quando da menção de voz. O norte-americanismo marca sua presença assídua na difusão do sucesso, sendo tratado como um item 
da cultura brasileira do qual leitores têm necessidade de tomar não apenas "nota", mas também incorporarem ao seus saberes cotidianos. A influência dos atores do sucesso norte-americano no plano midiático brasileiro parece estar relacionada a uma padronização do establishment do sucesso. A notícia Billie Holiday acentua a integração das importações estadunidenses como "propriedades" nacionais, porquanto, como um título, apela ao pré-construído "quem é" cuja resposta não se dá pelo acesso ao interdiscurso e sim pelo intradiscurso, ou seja, não pela constituição dos sentidos, mas pela sua formulação (ORLANDI, 2015, p. 30).

A construção Billie Holiday (feita apenas como epíteto artístico) segue as mesmas utilizadas em textos jornalísticos sobre celebridades brasileiras, salvo os casos em que se antecipa o conteúdo principal noticiado com elementos presentes na matéria, como Xuxa mostra seu lado solidário em SP (SOARES, 2017, p. 140). Portanto, se há uma estrutura relativamente estável de abrir os dizeres acerca de celebridades nacionais, quando se faz uso dela para enunciar o que quer que seja sobre uma personalidade estrangeira, cria-se o efeito de reconhecimento de sua importância no Brasil. Os mecanismos discursivos de formulação dos intradiscursos reconhecem a significação de organizações sintáticas e de seus constituintes, de modo que quando um componente carece de paridade com outros de volumosa circulação, no caso o nome, emprega-se o já consolidado hipocorístico ou o próprio nome como centro privilegiado de gravitação de préconstruídos, qual o título: Shirley Mallmann (ibid., p. 152).

"Há, portanto, determinações históricas, sociais e culturais na atribuição dos nomes e apelidos, vislumbrando sua condição de sujeito singular e sua integração e valorização social" (PIOVEZANI, 2012, p. 11) e, nesse traçado, Eleanora Fagan Gough passa a ser Billie Holiday e Lady Day. As formas de chamamento e evocação carregam a historicidade de suas condições de produção e emergência para o momento de retomadas. Há no uso desse procedimento o assujeitamento de quem recebe um ou mais nomes pelo fato de necessariamente se ver reconhecido na designação. Raros são os casos de quem escolhe como se chamará ou qual será sua alcunha, pois a sujeição está em sermos apreendidos pelas teias ideológicas da língua que se materializam nos discursos e, por conseguinte, nos nomes.

É na língua que se marcam as cores e tonalidades de que se revestem os nomes. A carga disfórica ou eufórica se presentifica na orientação de efeitos de sentido que a essas denominações se dá, tal como se pode verificar em Billie Holiday e Lady Day. De Billie Holiday a Adjetivos como "icone" e "autêntica" não bastam para descrever a importância de "Lady Day" constitui a cadeia de deslizamento metafórico, "Isso significa dizer que não se passa necessariamente de uma sequência discursiva a outra apenas por uma substituição, mas que as duas sequências estão, em geral, ligadas uma a outra por uma série de efeitos metafóricos" (PÊCHEUX, 2010, p. 99).

A cantora é recuperada em vários trechos da reportagem, de maneira que a estruturação desses seja ancoradouro de investigação. A ocorrência dos lexemas "icone", "autêntica" e importância conferem à cantora e a seus demais atributos legitimidade. "Essa que se apoia num reconhecimento e numa crença coletiva" e que "é da ordem de um direito em nome de um valor reconhecido" (CHARAUDEAU, 
2016, p. 15). Billie Holiday, também afamada pela acunha de Lady Day, não é qualquer personalidade do sucesso, adjetivos como "icone" e "autêntica" não bastam para descrever a importância dela. Ora, a carga eufórica está disseminada nos dizeres acerca da cantora e, somado a isso, os limites do efeito de seu sucesso são recobertos por ultrapassarem os possíveis sentidos contidos nas atribuições: icone e autêntica.

Não se pode deixar de notar a semelhança fonológica da antonomásia Lady Day com a da falecida princesa da Inglaterra, Diana, chamada popularmente de Lady Di. Essa ganhou um hipocorístico feito a partir de seu próprio nome, aquela recebeu um epíteto artístico por ser mais do que um ícone e autêntica em dar vida à música e ter sua influência sentida cem anos após seu nascimento. Contudo, qual o significado, para além da designação de uma celebridade do universo musical, de Lady Day em língua inglesa? O sintagma em questão significa, em língua inglesa, "festa da anunciação da virgem Maria", em 25 de março, também chamada Annunciation Day. Portanto, a gênese de seu uso está atrelada ao discurso religioso no qual Maria, uma virgem, é a mulher que dá à luz ao salvador do mundo, Jesus Cristo. A referida carga eufórica, mencionada anteriormente, encontra-se na interseção entre o efeito de sucesso e a legitimidade que aqui não é originada de valores (códigos de honra) ou institucional (um direito reconhecido por lei), mas uma legitimidade transcendental (do direito dos representantes religiosos, dos profetas) que permeia o discurso religioso (CHARAUDEAU, 2016, p. 14).

Posto isso, o discurso religioso e suas condições de produção são recortadas na discursivização do nome Lady Day, abrindo, no interdiscurso, efeitos de sentido possíveis de serem referidos a Billie Holiday.

Dessa perspectiva é interessante notar que, uma vez detectado esse caráter religioso atuando em diferentes processos de significação, podemos perceber que os vários discursos da cultura ocidental são atravessados pelo discurso religioso: o pedagógico, o jurídico, o acadêmico, o das minorias, o das "alternativas" etc. (ORLANDI, 1987, p. 9, grifo da autora).

A partir da observação acima e da verificação da presença do discurso religioso na construção do sucesso de Billie Holiday, é lícito reconhecer o efeito de $a$ anunciada, arregimentado no âmbito midiático, quando do emprego de Lady Day. A cantora é a anunciada tal qual a Maria bíblica, entretanto, diferente dela, traz ao mundo vida à música e sua influência sentida cem anos após seu nascimento. Para o mercado, parceiro efetivo da mídia, o recurso discursivo é estratégico porque soa convidativo aos ouvintes e consumidores. Como resultado, mais uma vez, as metáforas jogam discursivamente com o duplo sentido, com o equívoco, nessa dualidade sacro-pop, interpelando sujeitos outrora interpelados. Ora "Tudo o que é sólido e estável se volatiza, tudo o que é sagrado é profanado, e os homens são finalmente obrigados a encarar com sobriedade e sem ilusões sua posição na vida" (MARX; ENGELS, 1996, p. 69). Posições estas que comprometem o simbólico, o sentido e o político, porquanto, como se sabe em Análise do Discurso, o uso mais aparentemente cotidiano dos signos nunca é neutro.

Nessa perspectiva, a incorporação de traços do discurso religioso pelo discurso do sucesso faz jus a mercadologização do mundo anteriormente mencionado, 
sobretudo, dos artefatos de maior poder simbólico. Evocar figura tão significativa na sagrada narrativa ocidental para intitular uma personalidade midiatizada é, entre outras coisas, mostrar a ilimitada capacidade de sujeição pelo discurso e capitalizar o maior número de participantes de religiões para aderirem à celebridade. "As palavras "mudam de sentido" ao passar de uma formação discursiva para outra" (PÊCHEUX, 2011, p. 73, grifo do autor), contudo a historicidade presente nas condições de produção dos discursos pode ser recuperada via interdiscurso, de maneira que justamente os efeitos de sentido vinculados a essa historicidade possam ser utilizados no engendramento de outras formações discursivas, como neste caso.

Tinha apenas 17 anos cria, pelo circunstanciador adverbial apenas, uma moça jovem, contudo na década de 30 do século passado, aos 17 anos tanto mulheres quanto homens já eram considerados adultos e muitos já desempenhavam o papel de "chefes" de famílias. O sintagma 17 anos está também caracterizado pelo enunciado um pouco acima do peso que, por sua vez, é contraposto por perfeitamente bela e absolutamente desconhecida. Um pouco acima do peso, mas perfeitamente bela e absolutamente desconhecida, é o efeito de contraposição cumprindo seu ofício quando a "legitimação transcendental" de uma personalidade de sucesso passa pela higienização (e sacralização) do discurso da beleza.

Ademais, as lentes que captam a forma física da celebridade e lhe atribuem um pouco acima do peso, mas perfeitamente bela e absolutamente desconhecida são as de um agente do sucesso musical, logo, "entendem do assunto". Tanto é verdade que, por intermédio de John Hammond, de absolutamente desconhecida passou a Billie Holiday e a Lady Day. Deslinda-se o discurso autorizado, tal como lhe define Ferreira (2010, p. 95). Portanto, o aspecto físico do sujeito do sucesso precisa encarnar as prescrições impostas pelo discurso da beleza, que dita desde peso, estatura, cor de pele, cor de cabelo, cor de olhos, delineamento muscular, até como os itens anteriores devem estar dispostos. Outra vez, a pré-construção do próprio sucesso se apresenta no discurso da beleza. Billie Holiday passou no teste com a ressalva de encontrar-se um pouco acima do peso.

A voz da cantora é trazida à tona sendo caracterizada como única. A respeito dos dizeres sobre a voz, o adjetivo única pouco revela sobre a voz de Billie Holiday, já que cada voz é única no que tange a sua composição de traços, timbre, altura, velocidade, tessitura e potência. "Pour un artiste, un mélomane ou une cantatrice, la voix est caractérisée par son timbre, son ampleur, sa tessiture, son registre, son volume dans la gamme musicale, ses harmoniques dans une culture» ${ }^{5}$ (VASSE, 2010, p. 80). Entretanto, é uma voz única porque é uma "encantadora" voz do sucesso. A singularidade desta voz está aliada à perfeitamente bela, uma vez que a invisibilidade da primeira se manifesta na visibilidade da segunda.

O encontro entre o discurso sobre a voz (SOARES, 2019) e o discurso do sucesso (SOARES, 2017) nesta matéria jornalística, se dá sob circunstâncias

${ }^{5}$ Em tradução livre: "Para um artista, um amante da música ou um cantor, a voz é caracterizada pelo seu timbre, sua tessitura, seu registro, seu volume na escala musical, seus harmônicos em uma cultura". 
segundo as quais a criação de efeitos de sentido faz remissão à historicidade, que, então, precisa ser examinada. Melhor explicando: no trecho em que a voz única é enunciada, seu lugar de ocorrência também o é, qual seja, casa noturna. A voz única é confrontada na casa noturna em Nova York, um dos centros financeiros mais importantes dos Estados Unidos. O lugar em que "é única" evoca o discurso da prostituição. Casa noturna, ainda que atualmente tenha passado por transformações em seu emprego, equivale a bordel, a cabaré, a prostíbulo, a lupanar, à boate etc. Em vista disso, pode-se considerar a utilização de casa noturna como um eufemismo por se tratar de uma figura pública com consolidado prestígio midiático. Portanto, as condições de emergência da publicidade da voz de Billie Holiday estão conectadas as suas condições de vida, que precisam ser maquiadas, quando não apagadas, para integrarem o sucesso da cantora. $\mathrm{Ou}$ seja, "dizer de X é apagar outros dizeres. O sucesso é insidioso na utilização dos artefatos simbólicos e culturais" (SOARES, 2018b, p. 191).

A voz única está no lugar em que as demais vozes não são ouvidas, tampouco conhecidas. Uma voz reconhecida por quem tem a chancela da indústria da voz para fazê-lo. A voz única passa, ao deixar a casa noturna para ganhar as telas e microfones do mundo do sucesso, pela higienização e sacralização do discurso conservador da moral e dos bons costumes que, por todo seu aparato midiático e retórico-discursivo, lhe transforma na figura imaculada de Lady Day.

\section{CONSIDERAÇÕES}

Neste gesto de leitura, foi possível observar que a potencialização da interlocução de discursos no interior das notícias veiculadas pela revista Carta Capital é subsidiada por fatores intrínsecos à voz no discurso do sucesso. Tais fatores podem ser evidenciados em outros estudos arregimentados entorno do discurso do sucesso como fábrica estética de produção de sentidos (SOARES, 2020a), da estética da voz de sucesso, capitaneada pela subjetivação de uma estética da escuta (SOARES, 2020b). Assim como do próprio sentido da voz que se faz presente também na oratória a qual, por muito tempo, a voz foi tomada como sinônimo de prestígio e símbolo de sucesso (SOARES, 2018a; 2019). O exame empreendido neste artigo, bem como seu refinamento, pode ser mais bem compreendido se considerarmos as pesquisas já concluídas em torno dos dizeres sobre a voz de sucesso midiático e as que estão em vias conclusão que, de maneira delimitada, fazem-se presentes aqui por meio do próprio interdiscurso. Feitas essas considerações, inclinamos nosso olhar para o meio de disseminação dos dois textos analisados, Para ler Michael Jackson (2013) e Billie Holiday (2015).

Para considerarmos alguns pontos deste estudo como meio para reflexões significativas acerca do discurso do sucesso, observamos também que a revista Carta Capital veicula em sua seção Cultura reportagens sobre personalidades afamadas pela mídia e, consequentemente, pela sociedade em um discreto movimento publicitário. Parece não haver saída à publicidade, porquanto essa é agenciadora de recursos que lhe promove a continuidade, mesmo em veículo 
progressista de comunicação. Pelas buscas terem levado sempre ao âmbito da cultura, no que diz respeito à classificação dada pela revista às matérias, pode ser afirmado que as vozes do sucesso alcançaram o patamar de artefatos culturais. Os mesmos podem ser comercializados e, para tanto, precisam de visibilidade, quanto maior for essa, maior poderá ser sua comercialização.

Nas análises, foram percebidos os diversos expedientes a partir dos quais o discurso do sucesso lança mão para (re)criar celebridades, de maneira a lhes naturalizar o sucesso da voz pela estética vocal de sucesso que "é continuamente formada por estruturas enunciativas relativamente independentes, mas que anteriormente produziram marcas de sentidos que estabelecem também o padrão estético da escuta" (SOARES, 2020c, p. 6). A potente interlocução de discursos no interior das notícias, reforçando a proposição dialógica dos sentidos, defendida por Bakhtin/Volochínov (1981), perfaz trilhas intrínsecas à voz no discurso do sucesso, quais sejam: a beleza, a legitimidade, a autoridade, o enigma (para os menos conhecidos), a norte-americanização das Américas, a negritude, a feminilidade, o sagrado, a higienização etc. Isto é, uma série de trilhas que funcionam como "mecanismos recomendativos de correção, de aprimoramento e de esmero vocal" (SOARES, 2019, p. 278) para atingir a voz de sucesso (SOARES, 2018a; 2018b). Tais caminhos, postos em marcha como efeitos de sentidos necessários aos dizeres sobre os portadores de vozes do sucesso, mobilizam outras produções discursivas que se efetivam na língua, na ideologia e no inconsciente, visto que "Na produção do discurso, o sujeito sofre a tripla determinação: a da língua, a da ideologia e a do inconsciente" (BARONAS, 2011, p.16).

O discurso do sucesso examinado na revista se assenta, em boa parte, no universalismo norte-americano. Assim, há uma marcante recorrência da difusão de personalidades norte-americanas cuja fama tem de ser edificada também no Brasil. De todos os excertos, apenas um tratava de um brasileiro que faz sucesso no Japão. Nos demais recortes, a presença de cantores estadunidenses é flagrante, corroborando, entre outras coisas, uma possível importação do caráter propagandístico da música na América do Norte, como tal nos expõe Adorno (1999, p. 77) quando afirma que ela, “com todos os atributos do etéreo e do sublime que lhes são outorgados com liberalidade, é utilizada [...], como instrumento para a propaganda comercial de mercadorias que é preciso comprar para poder ouvir música".

Portanto, a voz, a música e o sujeito do sucesso constituem as bases de mecanismos de propagação do comércio de artefatos culturais, as vozes do sucesso. Notícias "inocentemente" trazidas a público com vistas a informar, a entreter e a influenciar leitores, encaminham-lhes para o mercado musical da indústria cultural, fomentando direta e indiretamente o consumo e a geração de produtos desse nicho e de outros a ele ligados. Pois, o mercado musical "se articula, por um lado, a uma indústria fonográfica independente, que ocupa nichos específicos, e, por outro, a todo um sistema de mídia formado por programas de rádio e televisão, revistas e jornais especializados em crítica musical, shows etc". (SÁ, 2007, 51-52; grifos da autora). 
Desse modo, o mercado associado à indústria musical é excepcionalmente amplo e vasto, como dimensiona Sá, consequentemente, articula a mídia, até a mais progressista, em seu favor, lhe fazendo repercutir a interseção do discurso do sucesso com o discurso sobre a voz. A raridade com a qual os dizeres sobre a voz são encontrados na revista, sobretudo no tocante às celebridades do mundo do canto, pode sinalizar para a naturalização meritocrática do sucesso nesse âmbito. A voz que é privilegiada, poderosa, infantil, única, alcança os píncaros do sucesso, não só por ter esses atributos, mas, antes, por esses lhe serem naturais e apropriados pela indústria musical para servir de mercadoria.

A voz, então, é uma mercadoria com idiossincrasias invisíveis aos olhos, porém perceptíveis aos sentidos sensoriais e, ainda mais, sentida e propagada no inconsciente como desejo:

L'élaboration lacanienne situe enfin la voix dans la dialectique du rapport de désir, mais du rapport de désir de l'Autre (au sens de «chez» l'Autre). (...) la voix se constituait comme objet, dans le désir de l'Autre impliqué dans la signification que celui-ci attribue aux cris ou aux vocalisations de l'enfant et dans la réponse qu'il leur donne. Si écouter c'est obéir, c'est dans la mesure où écouter c'est se soumettre au désir de l'Autre ${ }^{6}$ (POIZAT, 2001, p. 139; grifo do autor).

Ora, a voz é o objeto do desejo que, por sua vez, é matéria-prima consumida no mercado musical. Assim, a inscrição da voz dos sujeitos do sucesso no inconsciente não é tão somente o desejo de ouvi-la, mas o desejo de submeter-se a ela. Logo, o discurso do sucesso abre e põe em atuação seus inúmeros tentáculos para levar os sujeitos do sucesso e suas vozes a todos os lugares. A Carta Capital, nos textos analisados, se colocou a serviço do discurso do sucesso: mostrando-o, difundindo-o e propagando-o como informação cultural de interesse por parte de seus leitores. E, com isso, demonstrou contradição na sua prática jornalística, pois em 23 de outubro de 2013 , na edição impressa $\mathrm{n}^{\circ} 771$, sua reportagem de capa foi Como se constrói uma celebridade.

Essa matéria evidenciou uma crítica aos mecanismos de construção midiática do sucesso. Nela são mencionadas personalidades com grande capital de fama, como Pelé e Xuxa, e outras concebidas como subcelebridades. Em alguns trechos é possível constatar a mercadologização do sucesso: "A pessoa é um produto que eu vou lançar no mercado. É um projeto, diz o assessor Cacau Oliver. Beleza, astúcia e factoides são a parte da construção da fama"; "Com o declínio da centralidade da televisão e da imprensa para definir quem é famoso, uma nova economia da atenção surge. A lógica é viral, depende da aceitação do consumidor"; "Não adianta eu me vender como chique. O que vende mesmo é o bumbum". Esses recortes explicitam e demonstram como o sucesso é um tipo de influência exercida pela mídia na constituição de informações. O sucesso é um produto, um rosto, um bumbum ou uma voz, como vimos mais acima.

${ }^{6}$ Em tradução livre: "A elaboração lacaniana situa finalmente a voz na dialética da relação do desejo, mas da relação do desejo do outro (no sentido de "casa" do outro). (...) a voz se constituiu como objeto do desejo, no desejo do outro implicado na significação que atribui aos gritos ou vocalizações da criança e na resposta que a eles se dá. Se ouvir é obedecer, é na medida em que ouvir é se submeter ao desejo do Outro". 
Ao demonstrar o sucesso como uma construção midiática, a Carta Capital expôs uma das facetas da construção em massa de celebridades: a sistemática exposição pelas câmeras e holofotes, descuidando talvez do discurso. Por citar nomes, e até quantias, em uma "receita da fama", presta um relevante esclarecimento a seu público leitor, por outro lado, incorre no alvo da própria crítica. Perfaz, dessa maneira, ao longo desses anos pesquisados, a promulgação dos sujeitos do sucesso como uma auxiliar da indústria do sucesso. Um detalhe do artigo Como se constrói uma celebridade salta aos olhos e necessita ser observado: as celebridades e as subcelebridades de que o texto trata são todas brasileiras. Em momento algum são mencionadas personalidades norte-americanas ou de outras nacionalidades. Isso pode, a partir das considerações propostas aqui, querer dizer que é só no Brasil que existe um maquinário preparado para fazer aparecer sujeitos do sucesso.

A tecnologia de fabricação do sujeito do sucesso transcende um país. Tal como a própria revista revela, a despeito do conhecimento da engenharia da celebridade, ao reproduzir euforicamente os dizeres sobre as vozes do sucesso (sobretudo, de origem norte-americana), apresentando suas virtudes. Nesse diapasão, a Carta Capital soterra sua própria crítica para dar vazão a eventos sobre os sujeitos do sucesso noticiados na grande mídia, para, dessa feita, não a deixar passar a frente ou pelo menos manter certa igualdade na comunicação de "fatos importantes".

Portanto, a revista, de cunho progressista, na tentativa de elaborar artigos críticos e formadores de opinião para seu público, incorre na difusão do discurso do sucesso, de maneira a exaltar seus protagonistas, os sujeitos do sucesso, que, como visto nas análises, têm suas vozes apropriadas pela engenhosa indústria musical e transmitidas pela mídia, na qual "a voz ganha relevo por constituir um tipo de necessidade do sucesso midiático atribuído aos cantores e cantoras e, consequentemente, contribuindo para a construção de uma estética da voz de sucesso" (SOARES, 2020c, p. 16).

\section{REFERENCIAS}

ALTHUSSER, A. Aparelhos Ideológicos do Estado: Notas sobre os Aparelhos Ideológicos de Estado. Trad. Walter José Evangelista e Maria Laura Viveiros de Castro. 6 ed. Rio de Janeiro: Graal, 1992.

ADORNO, T. W. O fetichismo na música e a regressão da audição. In: ADORNO, T. W. Textos escolhidos. Trad. Luiz João Baraúna e João Marcos Coelho. São Paulo: Editora Nova Cultural, 1999.

ADORNO, T. W; HORKHEIMER, M. Dialética do esclarecimento: fragmentos filosóficos. Trad. Guido Antônio de Almeida. Rio de Janeiro: Zahar, 1985.

ANGENOT, M. O discurso social e as retóricas da incompreensão: consensos e conflitos na arte de (não) persuadir. Carlos Piovezani (org.) São Carlos, SP: EdUFSCar, 2015. 
BAKHTIN, M./VOLOCHÍNOV, V. N. Marxismo e Filosofia da Linguagem. 2 ed., Trad. Michel Lahud e Yara Frateschi Vieira. São Paulo: Hucitec, 1981.

BARONAS, R. L. Michel Pêcheux: um pensamento sob o signo da inquietude. In:BARONAS, R. L. Ensaios em análise de discurso: questões análico-teóricas. São Carlos, SP: EdUFSCar, 2011.

CHARAUDEAU, P. Discurso das mídias. Trad. Ângela M. S. Correa. 2 ed., Reimpressão. - São Paulo: Contexto, 2013.

CHARAUdEAU, P. A conquista da opinião pública. Trad. Ângela M. S. Correa. 2 ed., Reimpressão. - São Paulo: Contexto, 2016.

FERREIRA, L. A. Leitura e persuasão: princípios de análise retórica. São Paulo: Contexto, 2010.

LACAN, J. (1975). A verdade surge da equivocação. In: O Seminário Livro 1: Os escritos Técnicos de Freud. Trad. B. Milan. Rio de Janeiro: Jorge Zahar, 1986. p. 297-310.

MARTINO, L. M. S. Comunicação e identidade: quem você pensa que é. São Paulo: Paulus, 2010.

MARX, K.; ENGELS, F. Manifesto do Partido Comunista. 6 ed. Petrópolis, RJ: Vozes, 1996.

ORLANDI, E. Apresentação. In: ORLANDI, E. (org.). Palavra, fé, poder. Campinas, SP: Pontes, 1987.

PÊCHEUX, M. Análise automática do discurso. In: GADET, F.; HAK, T. (orgs.). Por uma análise automática do discurso: uma introdução à obra de Michel Pêcheux. Trad. Bethania S. Mariani [et. al.] 4 ed. Campinas, SP: Editora da Unicamp, 2010.

PÊCHEUX, M. Língua, linguagem, discurso. In: PIOVEZANI, C; SARGENTINI, V. (orgs.). Legados de Michel Pêcheux inéditos em análise do discurso. São Paulo: Contexto, 2011.

PÊCHEUX, M. Semântica e Discurso: uma crítica à afirmação do óbvio. Trad. Eni Puccinelli Orlandi et al. $5^{\text {a }}$ ed. Campinas, São Paulo: Editora da Unicamp, 2014.

PIOVEZANI, C. Identidades e metamorfoses na denominação dos jogadores de futebol no Brasil. In: Esporte e Sociedade: Identidades e metamorfoses. Ano 7, n 19, março 2012.

PLATÃO, F. S.; FIORIN, J. L. Para entender o texto: leitura e redação. 7 ed. São Paulo: Editora Ática, 1993.

POIZAT, M. Vox populi, vox Dei: voix et pouvoir. Paris: Métailié, 2001.

SÁ, S. M. A. P. Música eletrônica, DJs e consumo. In: BARROS FILHO, C.; CASTRO, G. (orgs.). Comunicação e práticas de consumo. São Paulo: Saraiva, 2007.

SOARES, T. B. Discursos do sucesso: a produção de sujeitos e sentidos do sucesso no Brasil contemporâneo. São Carlos, SP: Pedro \& João Editores, 2017.

SOARES, T. B.; PIOVEZANI, C. A voz do sucesso: um gesto de leitura dos dizeres acerca da voz na mídia. Revista Linguasagem, São Carlos, v.28, n.1, jan./jun. 2018, p. 135-147. 
SOARES, T. B. Vozes do sucesso: uma análise dos discursos sobre os vícios e virtudes da voz na mídia brasileira contemporânea. 312 f.: $30 \mathrm{~cm}$. Tese (doutorado em Linguística) - Universidade Federal de São Carlos, SP: 2018a.

SOARES, T. B (org.). Múltiplas perspectivas em Análise do Discurso: objetos variados. São Carlos, SP: Pedro \& João Editores, 2018b.

SOARES, T. B. Sentido da voz: uma análise das unidades do discurso presentes no campo da oratória. Revista Humanidades e Inovação v.6, n.8 - 2019. p. 269-280.

SOARES, T. B. As vozes midiatizadas: o sucesso como fábrica estética de produção de sentidos. São Paulo, SP: Revista CBTecLE nº 1 2020a. p. 1-16.

SOARES, T. B. Composição discursiva do sucesso: efeitos materiais no uso da língua. Palmas, TO: EDUFT, 2020b.

SOARES, T. B. A estética do sucesso vocal: discursos engendrados na construção de vozes de sucesso midiático. Florianópolis, SC: Anuário de Literatura, 2020c. p. 1-20.

VARGAS, M. V. Verbo e práticas discursivas. São Paulo: Contexto, 2011.

VASSE, D. L'arbre de la voix. France: Bayard, 2010.

WAJCMAN, G. Voix suivi de chut! Paris: Nous, 2012.

Recebido: 22/1/2019

Aceito: $9 / 10 / 2020$

Publicado: 13/10/2020 